Вестник ВГУ. Серия: Право

УДК 346.91(476)

DOI https://doi.org/10.17308/vsu.proc.law.2020.4/3182

\title{
ДОБРАЯ СОВЕСТЬ И ДОВЕРИЕ ИЛИ ЗАКОН?
}

\section{В. С. Каменков}

Международный научно-образовательный иентр медиации, прилирения и третейских процедур Белорусского государственного университета

Поступила в редакцию 21 октября 2020 г.

\begin{abstract}
Аннотация: исследуются основные принципь медиации, их значение для правового регулирования медиативных технологий, их практического приленения, использования в правотворческой деятельности, для научного исследования, а также действующее законодательство Республики Беларусь в сравнении с инылии государствали. Делаются выводы о возможности расширения областей общественных отношений, где прилениль медиативные приелы и технологии.

Ключевые слова: приниип, свобода, альтернатива, добровольность, добросовестность, доверие, равноправие, сотрудничество, беспристрастность, независилость, конфиденциальность.
\end{abstract}

Abstract: this article examines the basic principles of mediation and their significance for the legal regulation of mediation technologies, for their practical application, for use in lawmaking, for their scientific research, as well as the current legislation of the Republic of Belarus in comparison with other states, scientific publications on this topic. Conclusions are made about the possibility of expanding the areas of public relations, where mediation techniques and technologies are applicable, proposals are made.

Key words: principle, freedom, alternative, voluntariness, good faith, trust, equality, cooperation, impartiality, independence, confidentiality.

Принципы, или основополагающие руководящие положения, исходные директивные начала, присущи для многих нормативных правовых актов, отраслей права, правовой системы и в целом для методологии и методики правового регулирования общественных отношений, потому что они отражают сущность правовых норм, механизм их воздействия на регулируемые общественные отношения.

«Принципы права, или правовые принципы, пронизывают институты и нормы права и являются стержнем всей системы права. Они имеют важное значение для регулирования общественных отношений, юридической практики, осуществление права означает одновременно и воплощение в жизнь заложенных в нем принципов. Руководствуясь принципами, в том числе отраслевыми (основными) принципами, правильно применяются юридические нормы, принимаются обоснованные и законные решения. Они имеют существенное значение при подготовке и принятии нормативных правовых актов, внесении в них изменений и дополнений» ${ }^{1}$.

${ }_{1}^{1}$ Длитриева И. К. Значение основных принципов трудового права // Трудовое право в России и за рубежом. 2018. № 3. С. 13-16.

(C) Каменков В. С., 2020 


\section{Междисциплинарное сотрудничество...}

Исключением не является и закон о медиации ${ }^{2}$, ст. 3 которого посвящена принципам медиации. Основными принципами медиации являются: добровольность; добросовестность, равноправие и сотрудничество сторон; беспристрастность и независимость медиатора; конфиденциальность. В п. 2 этой статьи назван самостоятельный принцип: медиация основывается на доверии, которое стороны оказывают медиатору как лицу, способному обеспечить эфрфективное ведение переговоров.

Исследование принципов медиации имеет особое значение и в смысле открытия новых сфер общественных отношений, конфликты в которых поддаются медиативному регулированию.

Но не во всех зарубежных государствах указанный выше перечень принципов медиации повторяется в таком же полном объеме.

Например, в федеральном законе Российской Федерации № 193-Ф3³ указаны следующие принципы медиации: взаимное волеизъявление сторон, добровольность, конфиденциальность, сотрудничество, равноправие сторон, беспристрастность, независимость медиатора, но не назван принцип добросовестности.

В законе Республики Казахстан о медиации ${ }^{4}$ нет таких принципов, как добросовестность, доверие и сотрудничество сторон.

По-иному сформулирован также принцип независимости медиатора: недопустимость вмешательства в процедуру медиации (ст. 4). Еще одной особенностью казахстанского закона является наличие отдельных статей, посвященных раскрытию сущности каждого принципа медиации.

В Украине закон о медиации до настоящего времени не принят. Предпринятая попытка в 2019 г. результатов не дала, поскольку в Верховной раде Украины за проект закона не проголосовало необходимое большинство депутатов. В проекте закона Украины о медиации содержались следующие принципы: взаимное согласие сторон, добровольность участия, активность и самоопределение сторон, независимость и нейтральность медиатора, конфиденциальность информации о медиации (ст. 4) 5 .

В законе о медиации Республики Узбекистан ${ }^{6}$ нет принципов добросовестности и доверия.

${ }^{2}$ О медиации : закон Республики Беларусь от 12 июля 2013 г. № 58-3 (в ред. от 05.01.2016) // Национальный правовой интернет-портал Республики Беларусь. 2016. 14 янв. $2 / 2353$.

${ }^{3}$ Об альтернативной процедуре урегулирования споров с участием посредника (процедуре медиации) : федер. закон от 27 июля 2010 г. № 193-ФЗ (в ред. от 26.07.2019) // Собр. законодательства Рос. Федерации. 2019. № 30. Ст. 4099.

${ }^{4}$ О медиации : закон Республики Казахстан от 28 января 2011 г. № 401-IV (с изм. и доп. по состоянию на 27.12.2019). URL: https://online.zakon.kz/Document/?doc_id=30927376\#pos=3;-105 (дата обращения: 30.03.2020).

${ }^{5}$ O медиации : проект закона Украины № 3665. URL: https://mediationeurasia.pro/zakonodatelstvo/proekt-zakona-ukrainy-3665-o-mediacii (дата обращения: 30.03.2020).

${ }^{6}$ O медиации : закон Республики Узбекистан. URL: https://lex.uz/docs/3805229 (дата обращения: 30.03.2020). 


\section{Вестник ВГУ. Серия: Право}

В законе о медиации Республики Кыргызстан ${ }^{7}$ также нет принципов доверия и добросовестности, но имеется принцип нейтральности медиатора.

В модельном законе о медиации 8 дополнительно указан принцип активности медиатора (ст. 10), который означает, что при осуществлении процедуры медиации медиатор обязан использовать все доступные ему приемы, средства и способы убеждения сторон в достижении взаимоприемлемого соглашения по спору.

Такая неодинаковость в отношении к принципам медиации объяснима и понятна: в каждом государстве имеются свои правила, традиции и обычаи. При желании иметь общие подходы при формулировке принципов медиации нужно учитывать суверенитет государств.

Например, «...на законодательном уровне во Франции добровольность обращения к APC не закреплена как принцип. Более того, несмотря на законодательное требование наличия в большинстве случаев согласия сторон на проведение АРС, имеются и правовые конструкции, допускающие проведение указанных процедур без согласия на то сторон спора (обязательные процедуры)» .

Есть и иной подход к формированию принципов медиации и их перечню. «Характерной особенностью определений «медиации» и «медиатора» в законе является выражение через них основных принципов процедуры, таких как конфиденциальность и добровольность медиации, ответственность сторон, нейтральность медиатора. Такой подход делает немецкий закон более лаконичным и исключает необходимость включения в него отдельной статьи с перечислением принципов медиации» ${ }^{10}$.

Рассмотрим каждый из поименованных принципов медиации.

Добровольность - комплексный принцип, работающий на разных этапах развития медиативного процесса.

К сожалению, в белорусском законе о медиации этот принцип не раскрывается, поэтому здесь допустимы все виды толкования.

И. И. Красовская верно отмечает, что добровольность означает правило, согласно которому:

- стороны без какого-либо принуждения выбирают медиацию как способ разрешения их спора и медиатора в качестве нейтрального посредника в переговорах;

${ }^{7}$ O медиации : закон Кыргызской Республики от 28 июля 2017 г. № 161. URL: http://cbd.minjust.gov.kg/act/view/ru-ru/111668 (дата обращения: 31.03.2020).

${ }^{8}$ Модельный закон о медиации (внесудебном урегулировании споров : принят в г. Санкт-Петербурге 29 ноября 2013 г. на 39-м пленарном заседании Межпарламентской Ассамблеи государств - участников СНГ // Информационный бюллетень Межпарламентской Ассамблеи СНГ. Доступ из справ.-правовой системы «КонсультантПлюс».

9 Зверева H. С. Взаимодействие альтернативных методов урегулирования споров и гражданского судопроизводства в праве России и Франции / под ред. В. В. Яркова. М., 2017. С. 57-60.

10 Аболонин В. О. Закон Германии «О поддержке медиации и других форм внесудебного урегулирования конфликтов» (Mediations G) (с кратким пояснением) // Вестник гражданского процесса. 2013. № 5. С. 203-217. 


\section{Междисциплинарное сотрудничество...}

- участники медиации по своему желанию проводят переговоры в этой процедуре либо принимают решения о выходе из нее;

- стороны сами вырабатывают условия медиативного соглашения, добровольно заключают и исполняют его самостоятельно по доброй воле ${ }^{11}$.

$\mathrm{C}$ целью полного понимания принципа добровольности сюда можно дополнить и такое обстоятельство, как взаимное добровольное волеизъявление сторон.

Добровольность может расшифровываться в национальном законодательстве и через иные формулы, порой граничащие с иными принципами:

- никто не вправе принудить стороны к медиации, никто не вправе принудить медиатора к оказанию помощи посредством медиащии;

- стороны свободны в выборе вопросов для обсуждения взаимоприемлемого соглашения, «принуждение к примирению во время проведения процедуры медиации запрещается»;

- стороны свободны в выборе вопросов для обсуждения вариантов взаимоприемлемого соглашения, как предусмотренного законом, так и не предусмотренного законом, не нарушающего права и охраняемые законом интересы сторон и третьих лиц; «стороны вправе по своему усмотрению распоряжаться своими материальными и процессуальными правами, увеличить или уменьшить размер требований или отказаться от спора (конфликта)».

На наш взгляд, главное заключается в том, чтобы была добрая воля конфрликтующих сторон обратиться к медиативным технологиям и заключить медиативное соглашение, независимо от инициирующего это обращение субъекта. Не должно быть насилия и принуждения в медиации. В Директиве № 2008/52/ЕС Европейского парламента и Совета Европейского союза ${ }^{12}$ по этому поводу, например, сказано: «...посредничество - это организованный процесс, как бы он ни назывался, в котором две или более стороны пытаются добровольно достигнуть разрешения своего спора с помощью посредника. Этот процесс может быть начат сторонами, предложен или назначен судом или предписан правом государства-члена» (ст. 3).

И еще: «...посредничество, предусмотренное настоящей Директивой, должно быть добровольным процессом в том смысле, что стороны сами являются ответственными за процесс и могут организовать его так, как они желают, а также прекратить его в любое время. Тем не менее суд должен иметь возможность, в силу национального права, ограничивать процесс посредничества во времени. Кроме того, суды должны быть в со-

${ }^{11}$ См.: Красовская И. И. О добровольности медиации. Доступ из справ.-правовой системы «КонсультантПлюс».

${ }^{12} \mathrm{O}$ некоторых аспектах посредничества (медиации) в гражданских и коммерческих делах : директив № 2008/52/ЕС Европейского парламента и Совета Европейского союза : принята в г. Страсбурге 21 мая 2008 г. URL: http://eur-lex. europa.eu/ 


\section{Вестник ВГУ. Серия: Право}

стоянии привлечь внимание сторон к возможности посредничества всякий раз, когда это является подходящим решением».

Равноправие сторон - тоже комплексный принцип, действующий на всех стадиях развития медиативного процесса.

В белорусском законе о медиации данный принцип не раскрывается. Интересно, что в постановлении Правительства ${ }^{13}$ одна из правовых норм сформулирована императивно: «...медиатор своим участием в медиации способствует созданию атмосферы доверия, уверенности, безопасности и равноправия сторон» (п. 31). При отсутствии иных правовых норм и их толкований может сложиться неправильное представление, что обеспечение равноправия сторон - это обязанность только медиатора. На самом деле, это не так.

В постановлении Министерства юстиции Республики Беларусь ${ }^{14}$ уточняется: «...принцип равноправия заключается в обязанности медиатора обеспечить равное участие сторон в проведении медиации. При этом медиатор не вправе своими деяниями ставить какую-либо из сторон в преимущественное положение, равно как и умалять права и законные интересы одной из сторон» (п. 9).

В своем равноправии заинтересованы, прежде всего, сами конфликтующие стороны, обратившиеся добровольно к медиатору.

В законе Республики Казахстан о медиации учтены рекомендации модельного закона о медиации, и равноправию сторон посвящена отдельная ст. 6 , в которой говорится, что стороны медиации пользуются равными правами при выборе медиатора, процедуры медиации, своей позиции в ней, способах и средствах ее отстаивания, при получении информации, в оценке приемлемости условий соглашения об урегулировании конфликта и несут равные обязанности.

В законе о медиации Республики Узбекистан содержатся схожие правовые нормы о равноправии сторон.

Иными словами, равенство сторон в медиации следует понимать как обеспечение равных условий проведения медиативных процедур.

Другие критерии возможного неравенства сторон в медиации не имеют существенного значения. В противном случае медиация будет невозможна по значительному числу конфоликтов и споров. Но опыт зарубеж-

342 ных государств показывает обратное.

Например, досудебное разрешение налогово-правовых конфликтов имеет обязательный характер в таких странах, как ФРГ, Нидерланды, Япония, Франция, США, Италия и др. Использование таких неформальных средств, как медиация, реализовано, в частности, в Нидерландах, США, Бельгии. Кроме того, в США для разрешения налогово-правовых

${ }^{13}$ Об утверждении Правил проведения медиации : постановление Совета Министров Республики Беларусь от 28 декабря 2013 г. № 1150 // Национальный правовой интернет-портал Республики Беларусь. 2014. 5 янв. 5/38236.

${ }^{14}$ Об утверждении Правил этики медиатора : постановление Министерства юстиции Республики Беларусь от 17 января 2014 г. № 15 // Национальный правовой интернет-портал Республики Беларусь. 2014. 23 янв. 8/28273. 
Междисциплинарное сотрудничество...

конфликтов активно применяется арбитраж; в ФРГ, Великобритании используется переговорный процесс ${ }^{15}$. А ведь равенства между спорящими сторонами по налоговым конфликтам, как известно, нет по их статусному положению.

Сотрудничество сторон - не менее общий принцип медиации в сравнении с вышерассмотренными принципами. Более того, в этом принципе отражается суть медиации - без сотрудничества стороны не смогут договориться и прийти к соглашению, а без соглашения нет медиации.

В белорусском законе о медиации принцип сотрудничества также не раскрывается.

В упомянутом выше постановлении Министерства юстиции Республики Беларусь реализация этого принципа в основном возлагается почему-то только на медиатора:

«...медиатор при проведении медиации обязан соблюдать следующие основные принципы медиации... сотрудничества сторон» (п. 4);

«...медиатор должен проявлять благожелательное отношение к каждой из сторон, способствовать их сотрудничеству, а также содействовать сторонам в последовательном обмене документами, сведениями и сообщениями по обсуждаемым вопросам» (п. 8);

«...медиатор строит свои отношения с другими медиаторами на основе взаимного доверия, уважения, сотрудничества и поддержки» (п. 16).

Правильнее было бы говорить о заинтересованности сторон в сотрудничестве, а медиатор только способствует этому.

Модельный закон о медиации называет сотрудничество сторон основой процедуры медиации и достижения ее целей (ст. 7).

Закон о медиации Кыргызстана даже подчеркивает, что медиация проводится на основе конструктивного сотрудничества в целях согласования интересов спорящих сторон (ст. 5), а в законе Узбекистана сотрудничество сторон в медиации необходимо для достижения взаимоприемлемого решения в отношении спора (ст. 8).

Беспристрастность в белорусском законе о медиации незаслуженно только называется, но также не расшифровывается, а ведь без этого принципа медиация тоже невозможна.

В упоминаемом выше постановлении Министерства юстиции Республики Беларусь имеется такое уточнение: «...принцип добросовестности и беспристрастности заключается в отсутствии у медиатора корыстной или иной заинтересованности (прямой или косвенной) в исходе проведения медиации» (п. 6).

Принцип беспристрастности нашел отражение в законах многих государств СНГ. Например, в законе Узбекистана установлено, что медиатор должен быть беспристрастным, проводить процедуру медиации в интересах сторон и обеспечивать им равное участие в медиации, создавать необходимые условия для выполнения сторонами их обязанностей и осу-

${ }^{15}$ См.: Взаимосогласительные процедуры при разрешении налоговых споров в досудебном порядке / А. Ю. Ильин [и др.] ; отв. ред. А. Ю. Ильин. М., 2017. 


\section{Вестник ВГУ. Серия: Право}

ществления предоставленных им прав. При наличии обстоятельств, препятствующих независимости и беспристрастности медиатора, он должен отказаться от проведения процедуры медиации (ст. 9).

Независилость ледиатора в качестве одного из принципов его деятельности также упоминается в исследуемых законах.

Принцип независимости заключается в недопустимости вмешательства в деятельность медиатора, оказания морально-психологического и иного давления со стороны кого бы то ни было, утверждается в постановлении Министерства юстиции Республики Беларусь. К сожалению, в законе о медиации данный принцип почему-то только провозглашается.

В других государствах СНГ принципу независимости медиатора уделено достаточно внимания. Так, в законе Казахстана определено, что при проведении медиации медиатор независим от сторон, государственных органов, иных юридических, должностных и физических лиц. Медиатор самостоятелен в выборе средств и методов медиации, допустимость которых определяется законом о медиации (ст. 7).

Принципу конфбденциальности ледиации в законе о медиации заслуженно уделено достаточно много внимания. Без этого принципа значимость медиации может свестись к минимуму или нулевому результату. Поэтому это не только обозначение этого принципа в ст. 3, но и нормы ст. 16 о конфиденциальности информации, относящейся к медиации:

- обязанность сохранять конфиденциальность всей информации, относящейся к медиации, если стороны не договорились об ином, за исключением информации о заключении соглашений о применении медиации, о прекращении медиации;

- медиатор не вправе разглашать информацию, относящуюся к медиации и ставшую ему известной при ее проведении, без письменного согласия сторон.

В случае, если медиатор получил от одной из сторон информацию, относящуюся к медиации, он может раскрыть такую информацию другой стороне только с согласия стороны, предоставившей эту информацию;

- стороны, медиатор, а также другие лица, участвовавшие в медиации, независимо от того, связаны ли судебное разбирательство, третейское разбирательство со спором, который являлся предметом медиации, не вправе ссылаться, если стороны не договорились об ином, в ходе судебного или третейского разбирательства на информацию, полученную в ходе медиации:

о мнениях или предложениях, высказанных одной из сторон в отношении возможного урегулирования спора, равно как и о готовности одной из сторон принять предложение другой стороны об урегулировании спора;

заявлениях и признаниях, сделанных одной из сторон.

Исходя из постановления Министерства юстиции Республики Беларусь принцип конфиденциальности не распространяется на информацию о заключении соглашений о применении медиации, прекращении медиации (п. 10). 
Междисциплинарное сотрудничество...

В других государствах СНГ принцип конфиденциальности медиации также наличествует, но регулируется по-разному. В законе Кыргызстана установлена обязанность соблюдать конфиденциальность информации, ставшей им известной до начала и (или) в процессе проведения процедуры медиации только для медиатора и сотрудников организации медиаторов (ст. 7). Стороны медиации не вправе разглашать информацию, относящуюся к медиации, если они не договорились об ином.

В законе Узбекистана установлено, что не только медиатор, но и все участники медиации не могут быть допрошены в качестве свидетеля об обстоятельствах, ставших им известными в ходе медиации, а также от них не может быть истребована информация, относящаяся к медиации, за исключением случаев, предусмотренных законом (ст. 6).

Только в законе Казахстана говорится об ответственности за разглашение участником медиации сведений, ставших ему известными в ходе медиации, без разрешения стороны медиации, предоставившей эту информацию.

Принципы медиации, такие как добросовестность и доверие, имеются только в отечественном законе о медиации.

Правда, в законе о медиации эти принципы также не раскрываются. Но в постановлении Правительства установлена обязанность сторон, исполнять добровольно и добросовестно заключенное сторонами медиативное соглашение (п. 10). В постановлении Министерства юстиции Республики Беларусь упоминается и о добросовестности медиатора при исполнении своих обязанностей (подп.12.6).

Надо полагать, что принцип добросовестности распространяет свое действие на все этапы развития медиативного процесса и относится к деятельности всех его участников. Но формально прописать «добрую совесть» в правовых нормах не всегда получается. Можно вспомнить нечто подобное из Библии: «...любовь, радость, мир, долготерпение, благость, милосердие, вера, кротость, воздержание. На таковых нет закона» (Гал. $5: 22,23)$. Не все можно и нужно прописывать в законе, нужно еще включать и иные правила: совести, добра, порядочности, доверия и т. п. Эти качества для медиации очень важны.

О принципе доверия в законе сказано немного по тем же причинам: «Медиация основывается на доверии, которое стороны оказывают медиатору как лицу, способному обеспечить эффективное ведение переговоров. Медиатор своим участием в медиации способствует созданию атмосферы доверия, уверенности, безопасности и равноправия сторон».

Есть убеждение, что это лишь начало закрепления не только правовых, но и моральных принципов в медиации. За ними будущее, как и будущее нашего гражданского общества со снижением недоверия, недобросовестности и ответственности за сказанное слово, данное обещание, принятое решение.

Уже сейчас появляются реальные предложения, например о закреплении такого принципа, как «незлоупотребление правом». Можно говорить также о принципе содействия медиации со стороны судебной 


\section{Вестник ВГУ. Серия: Право}

власти $^{16}$ (сюда можно добавить и исполнительную власть), принципе профессионализма медиатора ${ }^{17}$ и иных.

Главное в другом: предоставить возможность развиваться медиации в государстве, обществе, коллективе, отношениях, чтобы восстановить и наладить взаимное доверие друг к другу, вернуть персональную ответственность субъекта за принимаемое решение, за данное слово.

${ }^{16}$ См.: Зенкевич А. З. Медиация в Польше и России // Lex russica. 2014. № 4. C. $469-476$.

${ }^{17}$ См.: Филатова У. Б., Архипкина А. С. Принцип профессионализма деятельности медиатора : тенденции развития российского законодательства и иностранный опыт // Нотариус. 2018. № 1. С. 41-47.

Международный научно-образовательный иентр медиаиии, примирения и третейских процедур Белорусского государственного университета

Каленков В. С., доктор юридических наук, проббессор

E-mail:v.kamenkov@gmail.com
International Scientific and Educational Center for Mediation, Reconciliation and Arbitration Procedures

Kamenkov V. S., Doctor of Legal Sciences, Professor

E-mail:v.kamenkov@gmail.com 